\title{
How COVID-19 Pandemic Influenced Non-formal Education Digital Transformation - SLAOTI Experience
}

\author{
Pia Stefano ${ }^{1}$, Juan Carlos Ocampo ${ }^{2 *}$, Ricardo Mosquera ${ }^{3}$, Ricardo \\ Trevisan $^{4}$, Alfonso Meza ${ }^{5}$ and Jamil Soni ${ }^{6}$ \\ ${ }^{1}$ Universidad Finis Terrae, Santiago, Chile \\ ${ }^{2}$ Complejo Asistencial Doctor Sótero del Rio, Santiago, Chile \\ ${ }^{3}$ Hospital de Especialidades Pediátricas, Caja del Seguro Social, Ciudad de Panamá, \\ República de Panamá \\ ${ }^{4}$ Centro Médico de Caracas, Caracas, Venezuela \\ ${ }^{5}$ Hospital Star Medica Infantil Privado, Ciudad de México, México; Hospital Español de \\ México, Ciudad de México, México \\ ${ }^{6}$ Pontificia Universidad Católica del Paraná, Curitiba, Brasil. Universidad Federal del \\ Paraná, Curitiba, Brasil \\ *Corresponding Author: Juan Carlos Ocampo, Pediatric Orthopaedic Department, \\ Complejo Asistencial Doctor Sótero del Río, Santiago, Chile.
}

Received: December 31, 2020

Published: January 22, 2021

(C) All rights are reserved by Juan Carlos Ocampo., et al.

\section{Abstract}

Background: Recent COVID-19 pandemic has generated exceptional changes in medical education. Processes carried out by different educational entities are important to be reported since they allow to improve teaching methods and thus professional quality. The main objective of this article was to report the experience and relevant data in our adaptation of non-formal education through digital transformation in pediatric orthopaedic field.

Methods: Webinars were broadcasted and uploaded to SLAOTI official website and its YouTube channel. Through YouTube Analytics tool, metrics were extracted regarding: webinars length, views, electronic display device and spread of access link; channel subscribers; digital and geographical visit origin and viewers age and gender since the channel creation on April $15^{\text {th }}$ to July $29^{\text {th }} 2020$.

Results: We evaluated 34 webinars. Average webinars length was 29 min with a Q\&A section of 29 min. Mobile phone was the most used display device and WhatsApp was the main social network used for access link spread. The channel had 13404 views and 884 subscribers. From total viewers almost $80 \%$ were less than 44 years and 82,1\% were male. Geographical visit origin showed that Mexico, Argentina and Venezuela were the countries with more visits and that an external link were the most used digital origin to access webinars.

Conclusions: Collaborative streaming platforms and social networks are useful in keeping non-formal educational exchange and in maintaining community communication and collaboration in pandemic times. In addition, some of them provides data that allows for continuously improving educational processes.

Keywords: Slaoti; Webinar; Pediatric Orthopaedic; Covid-19; Medical Education; Digital Transformation; Pandemic 


\section{Abbreviations}

SLAOTI: Latin American Society of Pediatric Orthopaedics and Traumatology.

\section{Introduction}

Global crisis caused by COVID-19 pandemic has not only generated a chaos in medical profession praxis, but it has also generated a great concern about formal and non-formal medical education continuity. Universities and institutions has been forced to close their gates and all activities that requires massive audience assistance, such as courses, congress or union meetings, had to be cancelled or postponed indefinitely.

With these new events arrival it presented itself a great challenge in order to quickly adapt the traditional way that medical education was being imparted towards a new model that would allow us to keep education continuity under consideration of all the restrictions that a global pandemic like this one can impose. As a result it emerged the need to rediscover teaching methods and to explore new platforms that would help us to spread knowledge to our colleagues in an affordable and safe way, following recommendations and social distancing required to avoid COVID-19 propagation.

Technology use has been the main character in the answer development to this particular challenge. Even though technology has been part of medical education for many years, present events has accelerated its internalization and acceptance in the medical community, because although digital transformation is associated to technology the path to true transformation is cultural and goes through people. Is within this framework that the Latin American Society of Pediatric Orthopaedics and Traumatology (SLAOTI), entity that groups up Latin American pediatric orthopedists, understood that it was time to take the step to a $100 \%$ digital transformation, with the aim of build and manage an online community by conducting webinars. This in the seek to answer the challenge of keeping continuity in academic training of medical professionals, helping to strengthen and generate value in the community in pandemic times.

Although experience of residency programs and fellows education staff in Orthopaedics during the present pandemic has been reported in the literature [1], experience of processes carried out in adaptation of non-formal education during COVID-19 global cri- sis has not been reported. This work objective is to describe SLAOTI experience in this stage of digital transformation, under the need to maintain continuous medical education in Pediatric Orthopaedics and Traumatology field.

\section{Materials and Methods}

From SLAOTI official website and its YouTube [2] (Google, Mountain View, California/US) channel, through its Analytics tool, most relevant metrics were extracted, according to our consideration, regarding to content evaluation and visitors characteristics since the channel was created on April 15th, 2020, to the last date analyzed, this being July 29, 2020.

The content evaluated in this period includes 34 webinars made by exhibitors representing multiple countries in Latin America. Of the 34 webinars, 20 were under direct SLAOTI organization, and includes a question and answer section, the other 14 were independent organization collaborative webinars sent to the society to be uploaded to SLAOTI channel (these collaborative videos were evaluated by SLAOTI directors board, prior to its publication, in order to maintain a quality editorial line).

\section{Results}

Length data in relation to webinars uploaded by SLAOTI were extracted (Table 1). A total of 1606 min with 33 seconds, equivalent to approximately 26,7 hours, of webinar was transmitted among the 34 videos. The average presentation length by the exhibitor was 29 minutes and 49 seconds. Of the 34 webinars, 20 had a live Q\&A section, average length of this section was 29 minutes and 37 seconds.

Views total number, among the 34 webinars, was 13404 with an average of 394 views per video uploaded to the channel (Figure 1).

Until July 29, 2020, a total of 884 channel subscribers was confirmed (Figure 2). Digital visits origin showed that an external link was the main form of access to webinars, followed by YouTube search engine and channels (Figure 3). Countries with more visits were: Mexico with 20,9\%, Argentina with 19\%, Venezuela with $17,4 \%$ and Peru with $14,8 \%$ (Figure 4). Data related to viewers age showed: $45,5 \%$ had between $25-34$ years, $31,2 \%$ had $35-44$ years, $12,3 \%$ had $45-54$ years and $11 \%$ had $55-64$ years. Gender was $17,9 \%$ female and $82,1 \%$ male. Mobile phone was the most com- 


\begin{tabular}{|c|c|c|c|}
\hline Webinar title & $\begin{array}{l}\text { Presentation } \\
\text { length (min) }\end{array}$ & $\begin{array}{l}\text { Q\&A length } \\
\text { (min) }\end{array}$ & Total length (min) \\
\hline Pediatric lateral condyle fracture & $21: 10$ & $37: 36$ & $58: 46$ \\
\hline Monteggia Fracture & $28: 16$ & 12:06 & $40: 22$ \\
\hline Postaxial hypoplasia of the lower extremity & 23:06 & $53: 12$ & $76: 18$ \\
\hline Surgical management of flatfoot in children with cerebral palsy & 18:40 & 7:02 & $25: 42$ \\
\hline Limb length discrepancy & 39:17 & 49:05 & $88: 22$ \\
\hline Tibial tubercle fracture in children & 17:09 & 35:08 & $52: 17$ \\
\hline Gait disorders & 29:00 & $50: 54$ & 79:54 \\
\hline Non accidental injuries in COVID times & $25: 55$ & 43:37 & $70: 32$ \\
\hline Pediatric acute hematogenous osteomyelitis & $42: 41$ & $7: 55$ & $50: 36$ \\
\hline Pelvic support osteotomy: evidence and perspectives & $31: 55$ & $54: 54$ & $85: 49$ \\
\hline Treatment alternatives for complex deformity around the knee & $20: 03$ & $27: 17$ & $47: 20$ \\
\hline Update in evaluation and treatment of malignant bone tumors in children & 43:07 & $14: 53$ & $58: 00$ \\
\hline Resection of tarsal coalitions & 23:49 & $25: 46$ & 49:35 \\
\hline Knee arthroscopy in childrens and teenagers: ¿when and why? & $21: 13$ & 38:41 & $59: 54$ \\
\hline Foot and myelomeningocele & $21: 49$ & $26: 37$ & $48: 26$ \\
\hline Unstable slipped capital femoral epiphysis & 41:02 & $27: 03$ & 68:05 \\
\hline Useful guidelines for short stature study & 38:05 & $19: 27$ & $57: 32$ \\
\hline Crouch gait in cerebral palsy & $37: 16$ & $17: 36$ & $54: 52$ \\
\hline Spasticity and baclofen pump & 29:19 & $26: 38$ & $55: 57$ \\
\hline Arthrogryposis in the lower extremity & $47: 12$ & $16: 58$ & $64: 10$ \\
\hline Bone lengthening basis* & 17:33 & & 17:33 \\
\hline Congenital pseudoarthrosis of the tibia and fibula: my point of view* & 25:33 & & $25: 33$ \\
\hline Epiphyseal cartilage distraction* & 19:46 & & 19:46 \\
\hline Pediatric osteosarcoma: advances in surgical treatment* & $52: 00$ & & $52: 00$ \\
\hline Humerus supracondylar fractures in childrens* & 20:00 & & 20:00 \\
\hline Imperfect osteogenesis: current approach* & 40:15 & & $40: 15$ \\
\hline Review of lower limb alignment test* & $52: 41$ & & $52: 41$ \\
\hline History of congenital foot conditions* & $17: 28$ & & $17: 28$ \\
\hline Hip Displacement in Cerebral Palsy* & $50: 40$ & & $50: 40$ \\
\hline Flexion deformities correction* & $34: 12$ & & $34: 12$ \\
\hline Flexible and flat foot management in children* & 11:47 & & $11: 47$ \\
\hline Proximal third of the femur in imperfect osteogenesis* & 29:48 & & $29: 48$ \\
\hline Coronal plane deformities: Genu valgum and genu varum* & $24: 41$ & & $24: 41$ \\
\hline Lower extremities rotational deformities* & $15: 40$ & & $15: 40$ \\
\hline TOTAL (min) & 1014:08 & 592:25 & 1606:33 \\
\hline Average (min) & $29: 49$ & $29: 37$ & $47: 15$ \\
\hline * corresponds to collaborative webinars & & & \\
\hline
\end{tabular}

Table 1: Webinars presented on SLAOTI channel and content length in analyzed period. 
mon electronic device used for visualization of the webinars (Figure 5). The main social network used was WhatsApp with $65,1 \%$ (Figure 6).

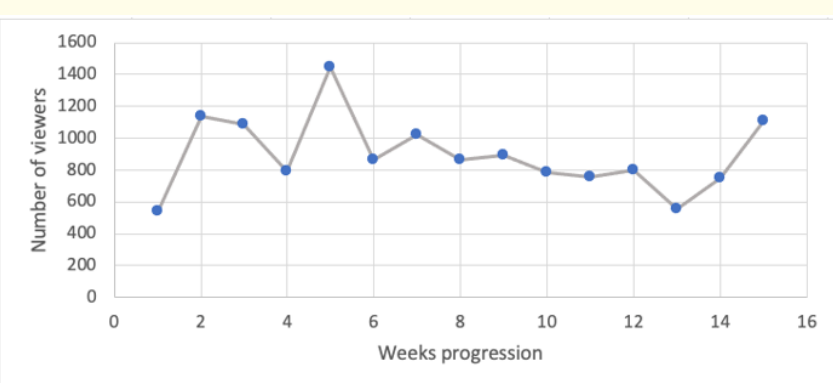

Figure 1: Number of channel viewers in relation to weeks progression.

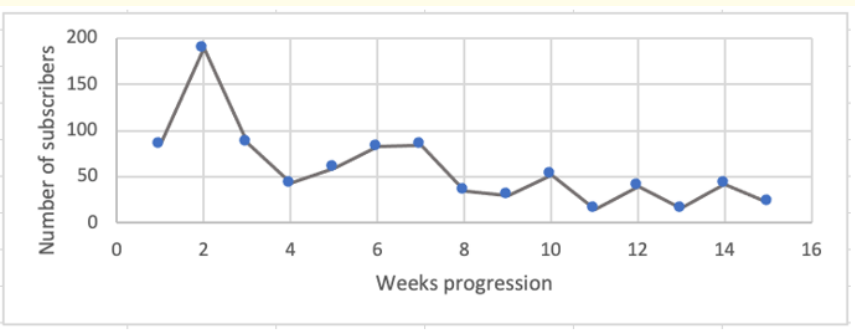

Figure 2: Number of channel subscribers in relation to weeks progression.

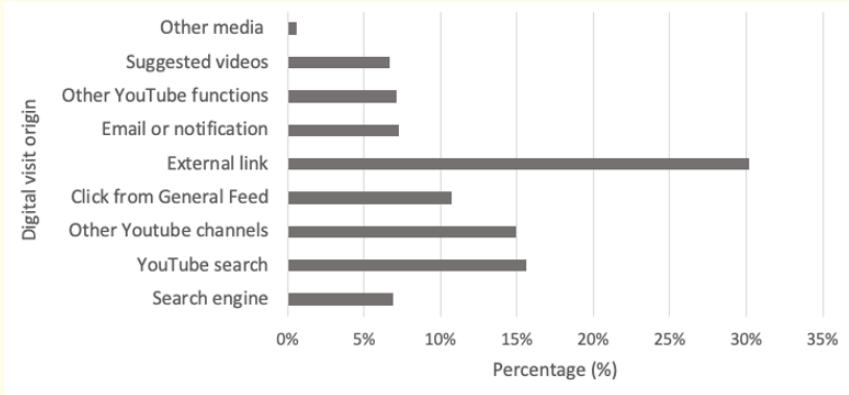

Figure 3: Digital visit origin to SLAOTI channel.

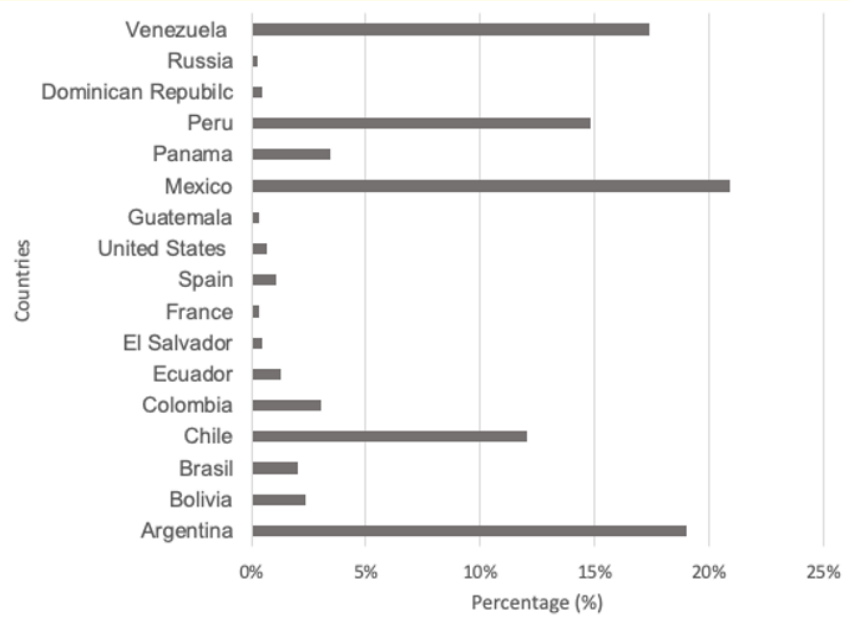

Figure 4: Geographical visits origin to the channel per country.

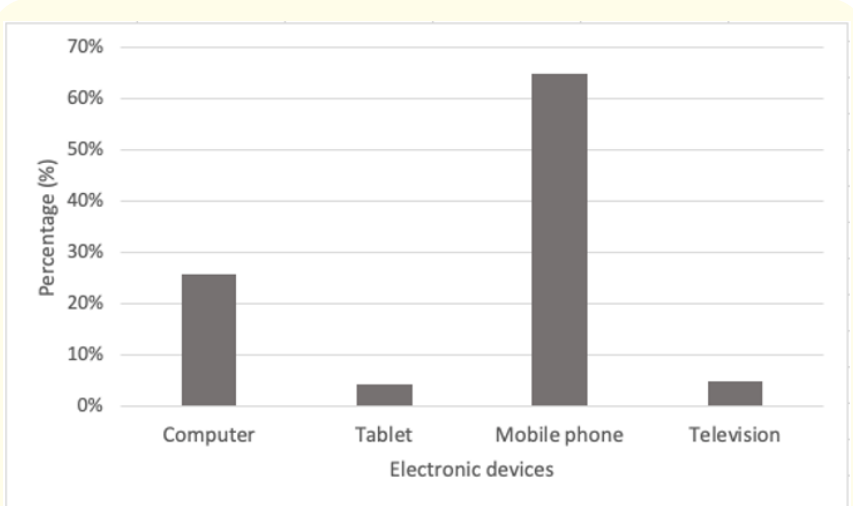

Figure 5: Electronic devices from which webinars were viewed.

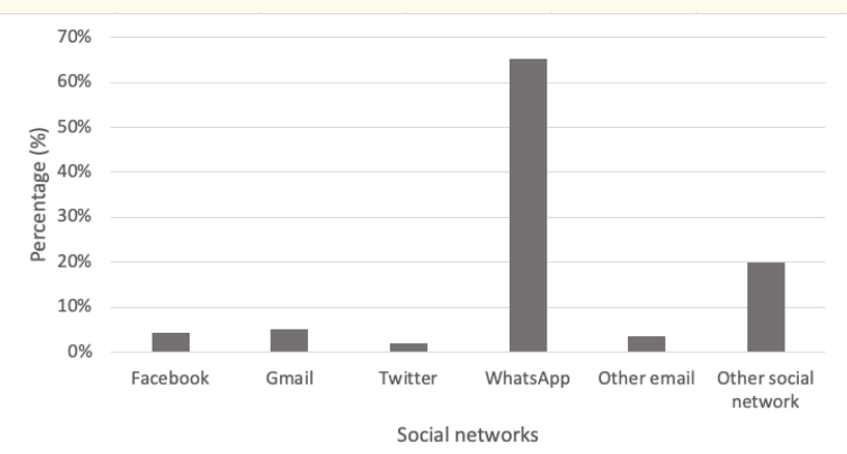

Figure 6: Social networks from which webinars link was shared. 


\section{Discussion}

Educational adaptations that have been made worldwide, both in formal and non-formal medical education, have as a fundamental basis the use and exploitation of technological tools, mainly, collaborative streaming platforms and social networks in order to maintain communication and education continuity in this social isolation times. However, organizational adaptations carried out internally in each institution are a necessary pillar for secondary educational adaptation to happen. The SLAOTI board of directors, in order to initiate digital transformation and manage to maintain cultural exchange of Latin American experiences, reorganized its traditional structure creating an education and communications commission with its respective members expansion in charge of this new area. When pandemic started, different companies, commercial entities, interest groups and independent exhibitors also joined in holding webinars, generating an oversupply of content. As a result of this overpopulation, which leads to topics repetition, exhibitors and coincidence of schedules, an overload and increased pressure towards assistants was evident. In order to optimize content scope at a Latin American level, SLAOTI took a moderator role organizing different topics and broadcast times to be presented, in addition to offering its YouTube channel and website www.slaoti. org to upload content made by others entities, with a collaborative intention, making webinars available to Latin American and Spanish-speaking world community.

In order to give widest spread possible and publicize webinars to be held, it was also necessary to create a SLAOTI official user profile on social networks such as Facebook, Instagram and Twitter; in addition to groups creation on WhatsApp and Telegram, for both internal and external communication with different Latin American entities that are part of the community.

Zoom [3] (Zoom Video Communications, San Jose, California/ US) is a well-known video conferencing tool that allows presenters screen to be shared with audience in real time, in addition to allow their participation. However, within its limitations is the number of participants allowed (100 participants in the paid PRO mode). In order to reach a wider audience and give content viewing after live broadcast option, transmission of SLAOTI webinars was extended from Zoom to YouTube. This allows unlimited participants to maintain interaction with the presenter through written comments that the webinar moderator can respond live or later.

In a survey conducted to Pediatric Orthopaedic Society of North America (POSNA) members on 2017 evidenced the already high social networks emergence in our field. When evaluating use of a professional profile, close to $80 \%$ of respondents had a profile on some social network (LinkedIn, ResearchGate, Facebook, etc.). Regarding YouTube platform, 33\% of POSNA members had a video published on this network in relation to their medical practice [4]. Despite high prevalence use of social networks, particularly audiovisual content, whether it is viewed on a live or deferred platform, there is little information about audience that consumes it. This creates a gap in necessary feedback to enhance our educational processes.

Some databases state that webinar attendees mostly prefer seminars of maximum 30 to 40 minutes length with only $10 \%$ preference for 60-minute seminars [5], this not including Q\&A section. A meta-analysis carried out in 2019 on webinars in higher education and professional training failed to conclude an optimal length, so it is their suggestion to continue based on published experience [6]. Under these parameters, average length of presented webinars would be considered adequate to keep active audience. In order to create greater audience engagement and give dynamism to exposed content, it is ideally recommended to have an instance of public interaction through, for example, a Q\&A section [7]. Webinars in which this interactive section was held, after formal topic presentation, average length was equal to the average of the presentation per se, which shows high interest from audience to actively participate and, especially, the great need to enrich from different professional experiences through discussion.

In addition to above, the number of channel views and subscribers, only confirms that content presented is relevant to SLAOTI community and that this relevance has been maintained over time.

Data on digital visits origin allows redirecting webinars promotion as well as advertising use, for example, through the same YouTube platform, which had $15,6 \%$ of the incomes. However, we 
can see that $30,2 \%$, the majority was provided with an external webinar access link. If required, geographic audience distribution can be used for further focus outreach efforts and reach widest community possible.

In most Latin American countries medicine career lasts 6 to 7 years [8]. SLAOTI webinars contents are mainly subspecialty; in this context it is likely to expect there would be little or no audience under 25 years. Regarding lower presence of advanced age subgroups in webinars, it can be explained by a general lower presence in social networks [9] in addition to one of the Analytics tool limitations; when extracting age data from audience, this tool does it through platform-registered users, so if part of the audience is not registered it will not be possible to extract this data.

Other relevant information for optimizing viewing by audience is the device through which webinars are viewed most frequently. We found that $65 \%$ of audience does it through their mobile phone, this data would help us improve slides format, for example by avoiding small letter or images size, in order to improve content delivery by the exhibitor.

Among data extracted we can find in which social network our content is shared after viewing it, being WhatsApp the main social network with $65,1 \%$ of the preferences. This application reaches an average penetration of $64 \%$ in Latin American countries, reaching up to approximately $80 \%$ in countries such as Costa Rica, Chile, Uruguay and Argentina [10]. This data has important relevance given that, when shared from YouTube channel to WhatsApp, video link can be re-sent from this second platform through message, email or simply to other contacts, improving spread and generating greater visibility and content reach. Interest in sharing videos confirms again content relevance.

However, despite many virtues that webinars have as an educational tool, they are not problems free. Attending congresses, courses or conferences allows professionals to detach themselves from work and enables them to give all their attention to content taught [11]. In current conditions we cannot control environment surrounding this educational settings where assistants are remotely connected.
Going further, it is necessary not to forget that excessive internet use can generate stress and alter important functioning areas [12], so self-monitoring will be essential to regulate the amount of destinated time to screens use [13] and thus maintain an adequate mental health, taking into account that much of screen time will be devoted to work or educational activities.

A limitation presented in this digital conversion experience has to do with the "double-edged" that mass broadcasting can bring in webinars organization, particularly when it comes to medical content. Given that SLAOTI covers such an extensive community, as Latin America can be, it makes it impossible to use audience restriction tools, allowing the possibility that people who do not belong to health care area view the content without censorship, which could generate ethical problems.

When using analysis tools, such as YouTube Analytics, there are limitations related to how metrics are extracted from the platform, metrics that allows us to monitor channel performance. For example, analysis of geographic origin is extracted from viewers IP address, while age and gender are extracted from platform-registered users. Under this type of limitation, it is possible that, in certain metrics, we can only analyze a users subset demographic data and it may, in some cases, not represent general composition of channel data traffic.

\section{Conclusion}

As a consequence of COVID-19 pandemic, digital transformation was accelerated and practically imposed in order to continue educational processes safeguarding our health.

SLAOTI, in its effort to keep alive cultural and educational exchange of Latin American region, saw the need to restructure itself, first in its organizational core to later focus its energies on entering this new stage of digital content, keeping pediatric orthopaedic community education up to date in this unprecedented circumstance. Online technology has been able to give us a means by which maintain knowledge spread and audience-presenter interaction. Furthermore, it provides us with tools that, through a couple of clicks and in real time, extracts data regarding audience reception of our content, information that allows us to generate feedback and 
to constantly optimize our educational processes. However, we believe that we must develop measures so that only health care providers have access to webinars and thus avoid hurting third parties sensitivities and protect any published material malicious use. Results from our work supports that conducting webinars with live audiences and subsequent content publication for delayed viewing are a useful and dynamic tool for updated medical knowledge spread at a time when sharing knowledge through traditional methods are not a possibility.

\section{Conflict of Interest}

- None of the authors received financial support for this study.

- The authors declare no conflicts of interest.

\section{Best webinar software}

\section{Bibliography}

1. An TW., et al. "How Are Orthopaedic Surgery Residencies Responding to the COVID-19 Pandemic? An Assessment of Resident Experiences in Cities of Major Virus Outbreak" .Journal of the American Academy of Orthopaedic Surgeons 28.15 (2020): e679-e685.

2. Youtube. Google. 901 Cherry Ave. San Bruno, CA 94066. USA (2020).

3. Zoom. 55 Almaden Boulevard, 6th Floor, San Jose, CA 95113 (2020).

4. Lander ST., et al. "Social Media in Pediatric Orthopaedics". Journal of Pediatric Orthopaedics 37.7 (2017): e436-439.

5. BigMarker. 12 Webinar Statistics you need to know. Medium (2020).

6. Gegenfurtner A and Ebner C. "Webinars in higher education and professional training: A meta-analysis and systematic review of randomized controlled trials". Educational Research Review 28 (2019): 1002932019.

7. Gharis L., et al. "Step By Step Process for Creating and Delivering Effective Webinars”. ResearchGate (2014).
8. Hanne C. "El proyecto Tuning latinoamericano: la experiencia del área de Medicina". Revista Hospital Clinico Universidad de Chile 25 (2013): 19-31.

9. Chen J. "Social media demographics to inform your brand's strategy in 2020". Sprout Social (2020).

10. Chevalier S. “¿Que tan popular es WhatsApp en Latinoamérica?". Satatista (2019).

11. Plancher KD., et al. "The Changing Face of Orthopedic Education: Searching for the New Reality After COVID-19". Arthroscopy, Sports Medicine, and Rehabilitation 2.4 (2020): 295-298.

12. World Health Organization. ICD-11 for Mortality and Morbidity Statistics (2019).

13. Király 0., et al. "Preventing problematic internet use during the COVID-19 pandemic: Consensus guidance". Comprehensive Psychiatry 100 (2020): 1-4.

\section{Assets from publication with us}

- Prompt Acknowledgement after receiving the article

- Thorough Double blinded peer review

- Rapid Publication

- Issue of Publication Certificate

- High visibility of your Published work

Website: https://www.actascientific.com/

Submit Article: https://www.actascientific.com/submission.php

Email us: editor@actascientific.com

Contact us: +919182824667 